\title{
EMPOWERMENT EDUCATION, PEER SUPPORT TERHADAP PERILAKU PENCEGAHAN CACAT DI RS KUSTA SUMBERGLAGAH
}

\author{
Taufan Arif*, Joni Haryanto*, Esty Yunitasari * \\ *Fakultas Keperawatan Universitas Airlangga Kampus C Mulyorejo Surabaya \\ Email: taufanarif1990@gmail.com
}

\begin{abstract}
Leprosy disease is caused by Mycobacterium leprae which attacks the skin and peripheral nerves. Currently leprosy still remains a world problem. Leprosy patients should not experience severe structural and functional damage. The combination of the empowerment education, peer support can improve symptoms and signs of impairment, behavioral prevention defects. The objective of this study was describes empowerment education, peer support to behavior prevention of dissability. This study used true experimental randomized pre-post test control group design. The sampel was recruited using simple random sampling consisting of 16 respondents. The independent variable are empowerment education, peer support. The dependent variable are knowledge of disability prevention, attitude of disaility prevention, action of medication compliance. The data were collected by distributing questionnaires and check card patient treatment. Data were analized by Mann-Whitney Test and Wilcoxon Signed ranked Test. The result showed that 1) There is influence on knowledge, 2) There is influence on attitude , 3) There is influence on medication adherence. Supportive interventions through empowerment education, peer support can help leprosy patients in the treatment process. Proven knowledge, attitude, adherence to medication, and self efficacy intervention group increased after given intervention. Suggestions for further research is to examine the development of leprosy impairment prevention models based on other nursing theories and with a longer duration of study.
\end{abstract}

Keyword: empowerment education, home-based self care, peer support leprosy, impairment, behavioral, self efficacy

Abstrak: Penyakit kusta disebabkan oleh Mycobacterium leprae yang menyerang kulit dan saraf perifer. Saat ini penyakit kusta masih menjadi masalah dunia. Pasien kusta tidak harus mengalami kerusakan struktural dan fungsional parah. Kombinasi dari tiga bentuk intervensi empowerment education, home-based self care, peer support dapat memperbaiki gejala dan tanda gangguan, cacat pencegahan perilaku, dan self efficacy. Tujuan dari penelitian ini adalah untuk menjelaskan empowerment education, peer support terhadap perilaku pencegahan cacat. Penelitian ini menggunakan true experimental randomized pre-post test control group design. Sampel diambil dengan menggunakan simple random sampling yang terdiri dari 16 responden. Variabel bebasnya adalah empowerment education, peer support. Variabel dependennya adalah pengetahuan tentang pencegahan kecacatan, sikap pencegahan cacat, tindakan kepatuhan minum obat. Data dikumpulkan dengan menyebarkan kuesioner dan kartu cek perawatan pasien. Data dianalisis dengan uji Mann-Whitney Test dan Wilcoxon Signed. Hasil penelitian menunjukkan bahwa 1) Ada pengaruh terhadap pengetahuan, 2) Ada pengaruh terhadap sikap, 3) Ada pengaruh terhadap kepatuhan minum obat. Intervensi yang mendukung melalui empowerment education, peer support dapat membantu pasien kusta dalam proses pengobatan. Terbukti pengetahuan, sikap, kepatuhan terhadap pengobatan, dan kelompok intervensi mengalami peningkatan setelah diberi intervensi. Saran untuk penelitian lebih lanjut adalah untuk menguji perkembangan model pencegahan kerusakan kusta berdasarkan teori keperawatan lainnya dan dengan durasi studi yang lebih lama. 


\section{Kata Kunci: education, home-based self care, peer support, perilaku, self efficacy, impairment}

\section{PENDAHULUAN}

Penyakit kusta merupakan salah satu penyakit kulit yang bersifat menular yang dapat menimbulkan masalah yang kompleks, tidak hanya dari segi medis tetapi juga meluas sampai masalah sosial (Loetfia, 2007). Kusta disebabkan kuman mycobacterium leprae yang menyerang kulit dan saraf tepi dapat menyebabkan kecacatan seumur hidup. WHO mengatakan bahwa penyakit kusta masih menjadi masalah dunia. Klien kusta tidak harus mengalami kerusakan struktur dan fungsi yang berat, keterbatasan aktifitas yang parah, dan partisipasi aktif dalam program eliminasi kusta (Kemenkes RI, 2015; Dirjen PP\&PL, 2012; Dinkes Jatim, 2012). Kebanyakan klien kusta mengalami impairment (70\%), activity limitation (60\%), dan participation problem (60\%) (Brakel et al, 2012; Dirjen PP\&PL, 2012; Masayoshi, 2010). Empowerment Education telah berhasil meningkatkan self efficacy perawatan diri klien kusta (62,5\%) (Wahyuni, 2014). Home-based self care dalam Enhance Global Strategy WHO diyakini dapat mencegah kecacatan kusta karena penyandang cacat dapat melakukan perawatan diri secara mandiri yang dipantau secara ketat (WHO, 2009; Dirjen PP\&PL, 2012). Peer Support mampu meningkatkan kepatuhan minum obat klien (63\%) (Yuswanto, 2015).

Di Jawa Timur sendiri, Prevalensi rate penyakit kusta Tahun 2016 1,24 per 10.000 penduduk. Penemuan klien baru Tahun 2015 sebanyak 3.946 orang, dan Tahun 2016 sebanyak 4.809 orang. Angka cacat klien baru Tahun 2016 sebanyak 485 orang (14\%) cacat derajat 1, dan 351 orang $(10 \%)$ cacat derajat 2 dari target sebesar $<5 \%$ (Dinas Kesehatan Provinsi Jawa Timur, 2016).

Data di Tingkat RS sumberglagah sendiri, Tahun 2015 cacat derajat 1 tidak ada dan 3 orang (13\%) cacat derajat 2, dan Tahun 2016 sebanyak 11 orang $(50 \%)$ cacat derajat 1 dan 2 orang $(9 \%)$ cacat derajat 2 dari target sebesar $<5 \%$ (Dinas Kesehatan Provinsi Jawa Timur, 2016).

Studi pendahuluan peneliti pada bulan Desember 2016 dari data Rekam Medis Prevention of Disability (PoD) dan interview langsung, impairment dari 6 klien yang aktif pengobatan MDT didapatkan sebesar $33 \%$ mengalami perubahan dri dejat 1 menjadi derajat 2 saat pengambilan data oleh peneliti. Catatan Rekam medis dan interview untuk kepatuhan minum obat didapatkan hasil sebanyak $43 \%$ tidak teratur dalam minum obat yang dibuktikan dari catatan pengambilan obat yang melebihi waktu 28 hari, dan sebanyak $67 \%$ kurang memahami pengelolaan, pengobatan penyakit kusta dan pencegahan cacat kusta.

Upaya-upaya pencegahan kecacatan dapat dilakukan baik di rumah, puskesmas, atau unit pelayanan rujukan (Dirjen PP\&PL, 2012). Penelitian yang dilakukan oleh Wewengkang menjelaskan bahwa pengetahuan, diagnosis dini, keteraturan berobat dan perawatan diri merupakan faktor-faktor yang mempengaruhi tingkat kecacatan yang dialami klien (Wewengkang, 2016). Penelitian Susanto tentang faktor yang berhubungan dengan kecacatan kusta menjelaskan bahwa, terdapat beberapa faktor yang mempengaruhi angka kejadian tingkat kecacatan pada penderita kusta, antara lain: umur, pendidikan, tipe kusta, reaksi, pengetahuan, ketaatan berobat, diagnosis, dan perawatan diri. Klien dengan pengetahuan yang baik akan lebih bertanggungjawab terhadap pengobatannya (Susanto, 2006).

Penelitian Wahyuni (2014) tentang empowerment education terdapat perbedaan yang signifikan terhadap self 
efficacy klien kusta. Hasil kepatuhan minum obat tidak ada perbedaan yang signifikan. Hasil kualitas hidup menunjukkan terdapat perbedaan yang signifikan (Wahyuni, 2014). Penelitian.

Penanganan kusta bersifat komprehensif. Maka dari itu, kombinasi intervensi yang terdiri education, peer support dalam memperbaiki gejala dan tanda impairment, meningkatkan perilaku pencegahan cacat, dan self efficacy klien kusta masih perlu dilakukan penelitian.

\section{METODE}

Desain penelitian menggunakan rancangan true experimental randomized pre-post test control group design. Populasi penelitian ini adalah penderita kusta yang terdaftar di RSK Sumberglagah yang sudah memenuhi criteria homogenitas sebanyak 16 orang. Sampel penelitian sebanyak 16 orang yang dibagi ke dalam kelompok intervensi dan kelompok kontrol. Cara pengambilan responden menggunakan simple random sampling.

Variabel independent penelitian ini adalah empowerment education, homebased self care, peer support, sedangkan variabel dependent adalah pengetahuan pencegahan cacat, sikap pencegahan cacat, tindakan kepatuhan minum obat, self efficacy, impairment. Instrumen yang digunakan untuk variabel independent adalah Satuan Acara Kegiatan (SAK), sedangkan variabel dependent menggunakan kuesioner tertutup, dan menggunakan pengukuran biologis invivo pada variabel impairment. Kuesioner telah diuji validitas dan reliabilitasnya dengan uji Pearson correlation dan Cronbach Alpha. Data yang terkumpul kemudian dianalisis memakai uji mann whitney untuk 2 kelompok yang tidak berpasangan, dan wilcoxon sign ranked test untuk uji 2 kelompok berpasangan dengan nilai signifikan 0,05.

\section{HASIL DAN PEMBAHASAN}

\section{a. Hasil}

Tabel 1. Tingkat pengetahuan responden

\begin{tabular}{|c|c|c|c|c|}
\hline \multirow[t]{2}{*}{$\begin{array}{l}\text { Tingkat } \\
\text { Pengetahuan }\end{array}$} & \multicolumn{2}{|c|}{$\begin{array}{l}\text { Kelompok } \\
\text { Intervensi }\end{array}$} & \multicolumn{2}{|c|}{ Kelompok Kontrol } \\
\hline & Pre test & $\begin{array}{l}\text { Post } \\
\text { test }\end{array}$ & $\begin{array}{l}\text { Pre } \\
\text { test }\end{array}$ & Post test \\
\hline Baik & 2 & 7 & 3 & 1 \\
\hline Cukup & 3 & 1 & 3 & 6 \\
\hline \multirow[t]{4}{*}{ Kurang } & 3 & - & 2 & 1 \\
\hline & \multicolumn{4}{|c|}{ Pre test mann whitney $p: 0.540$} \\
\hline & \multicolumn{2}{|c|}{$\begin{array}{l}\text { Wilcoxon sign } \\
\text { ranked p: } 0.014\end{array}$} & \multicolumn{2}{|c|}{$\begin{array}{l}\text { Wilcoxon sign ranked } \\
\text { p: } 0.655\end{array}$} \\
\hline & \multicolumn{4}{|c|}{ Post test mann whitney $p: 0.028$} \\
\hline
\end{tabular}

Tabel 2. Tingkat sikap responden

\begin{tabular}{lllll}
\hline Tingkat & \multicolumn{2}{l}{ Kelompok Intervensi } & \multicolumn{2}{l}{ Kelompok Kontrol } \\
\cline { 2 - 5 } Sikap & Pre test & Post test & Pre test & Post test \\
\hline Tinggi & 2 & 8 & 2 & 3 \\
Sedang & 6 & - & 6 & 5 \\
Rendah & - & - & - & - \\
\hline \multirow{5}{*}{} & Pre test mann whitney p: 1.000 \\
\cline { 2 - 4 } & Wilcoxon sign ranked & Wilcoxon sign ranked \\
& p: 0.014 & p: 0.317 \\
\cline { 2 - 4 } & Post test mann whitney p: 0.038 \\
\hline
\end{tabular}

Tabel 3. Tingkat Tindakan patuh

\begin{tabular}{lllll}
\hline Tingkat & \multicolumn{2}{l}{ Kelompok Intervensi } & Kelompok Kontrol \\
\cline { 2 - 5 } Tindakan & Pre test & Post test & Pre test & Post test \\
\hline Tinggi & 3 & 8 & 4 & 3 \\
Sedang & 3 & - & 4 & 5 \\
Rendah & 2 & - & 0 & - \\
\hline \multirow{5}{*}{} & \multicolumn{2}{l}{ Pre test mann whitney p: 0.358} \\
\cline { 2 - 4 } & \multicolumn{2}{l}{ Wilcoxon sign ranked } & Wilcoxon sign ranked \\
& p: 0.038 & p: 0.317 \\
\cline { 2 - 4 } & Post test mann whitney p: 0.009 \\
\hline
\end{tabular}

Tabel 4. Tabulasi silang pengetahuan

\begin{tabular}{ccccc}
\hline \multicolumn{2}{c}{ Pengetahuan } & \multicolumn{2}{c}{ Post test } & \multirow{2}{*}{ Total } \\
\cline { 3 - 4 } K. Intervensi & \multicolumn{2}{c}{ Baik } & Cukup & \\
\hline \multirow{2}{*}{ Pre } & Baik & 2 & - & 2 \\
test & Cukup & 2 & 1 & 3 \\
& Kurang & 3 & - & 3 \\
\hline \multicolumn{2}{c}{ Total } & 7 & 1 & 8 \\
\hline
\end{tabular}

Tabel 5. Tabulasi silang pengetahuan

\begin{tabular}{cccccc}
\hline Pengetahuan & \multicolumn{3}{c}{ Post test } & \multirow{2}{*}{ Total } \\
\cline { 2 - 4 } K. Kontrol & Baik & Cukup & kurang & \\
\hline \multirow{2}{*}{ Pre $\quad$ Baik } & 1 & 2 & - & 3 \\
test Cukup & - & 2 & 1 & 3 \\
& Kurang & - & 2 & - & 2 \\
\hline Total & 1 & 6 & 1 & 8 \\
\hline
\end{tabular}


Tabel 6. Tabulasi silang sikap

\begin{tabular}{ccccc}
\hline \multicolumn{2}{c}{ Sikap Kelompok } & \multicolumn{2}{c}{ Post test } & \multirow{2}{*}{ Total } \\
\cline { 2 - 4 } \multicolumn{2}{c}{ Intervensi } & Tinggi & Sedang & \\
\hline Pre & Tinggi & 2 & - & 2 \\
test & Sedang & 6 & - & 6 \\
\hline \multicolumn{2}{c}{ Total } & 8 & - & 8 \\
\hline
\end{tabular}

Tabel 7. Tabulasi silang sikap

\begin{tabular}{ccccc}
\hline \multicolumn{2}{c}{$\begin{array}{c}\text { Sikap Kelompok } \\
\text { control }\end{array}$} & \multicolumn{2}{c}{ Post test } & \multirow{2}{*}{ Total } \\
\cline { 2 - 4 } & Tinggi & Sedang & \\
\hline Pre & Tinggi & 2 & - & 2 \\
test & Sedang & 1 & 5 & 6 \\
\hline \multicolumn{2}{c}{ Total } & 3 & 5 & 8 \\
\hline
\end{tabular}

Tabel 8. Tabulasi silang tindakan

\begin{tabular}{ccccc}
\hline \multirow{2}{*}{ Tindakan } & \multicolumn{2}{c}{ Post test } & \multirow{2}{*}{ Total } \\
\cline { 3 - 4 } K. Intervensi & Tinggi & Sedang & \\
\hline \multirow{2}{*}{ Pre } & Tinggi & 3 & - & 3 \\
test & Sedang & 3 & - & 3 \\
& Rendah & 2 & - & 2 \\
\hline \multicolumn{2}{c}{ Total } & 8 & - & 8 \\
\hline
\end{tabular}

Tabel 9. Tabulasi silang tindakan

\begin{tabular}{ccccc}
\hline \multicolumn{2}{c}{ Tindakan } & \multicolumn{2}{c}{ Post test } & \multirow{2}{*}{ Total } \\
\cline { 2 - 4 } K. Kontrol & Tinggi & Sedang & \\
\hline Pre & Tinggi & 3 & 1 & 4 \\
test & Sedang & - & 4 & 4 \\
\hline \multicolumn{2}{c}{ Total } & 5 & 5 & 8 \\
\hline
\end{tabular}

Hasil penelitian menunjukkan bahwa saat dilakukan pre-test responden pada kelompok intervensi berada pada tingkat cukup dan rendah, sedangkan kelompok kontrol berada pada tingkat cukup dan tinggi. Hasil post test responden pada kelompok intervensi berada pada tingkat baik, sedangkan kelompok kontrol berada pada tingkat cukup.

Analisis empowerment education, homebased self care, dan peer support terhadap pengetahuan pencegahan cacat kusta menunjukkan adanya pengaruh intervensi tersebut.

\section{b. Pembahasan}

Pengetahuan merupakan hasil tahu setelah orang mengadakan penginderaan terhadap suatu objek (Notoatmodjo, 2010). Pengetahuan juga dipengaruhi oleh beberapa faktor, menurut Azwar (2007) faktor tersebut meliputi pendidikan, minat, intelegensi, media massa, pengalaman, sosial budaya, lingkungan, penyuluhan, informasi.
Prinsip Pencegahan cacat dan bertambah beratnya cacat pada dasarnya adalah $3 \mathrm{M}$, yaitu (1) memeriksa mata, tangan dan kaki secara teratur; (2) melindungi mata, tangan dan kaki dari trauma fisik, dan (3) merawat diri (Sjamsoe, 2003; Dirjen PP\&PL, 2012).

Empowerment education adalah suatu edukasi yang diberikan kepada klien dengan pendekatan empowerment (pemberdayaan yang berfokus pada klien). Castilo et al (2010) dalam Wahyuni 2014) menjelaskan bahwa empowerment education disebut juga self-management education yang terdiri dari strategi pengajaran dengan pendekatan problem solving dan sharing informasi dan pengetahuan untuk mencapai pengelolaan yang baik terhadap penyakitnya.

Hal ini diperkuat penelitian menjelaskan bahwa self-management education akan meningkatkan pengetahuan, dukungan keluarga, dan stigma diri, dan kepatuhan berobat seseorang dengan penyakit kronis seperti penyakit kusta. Perbaikan pengetahuan tentang kusta didapat dari learning proses sehingga menimbulkan pemahaman (Mufarokhah, 2014; Putri 2016).

Hasil intervensi penelitian ini diperkuat penelitian Rawlett E Kristen (2011), sebuah edukasi seperti empowerment education akan berpengaruh terhadap aspek-aspek pokok health belief model seperti kerentanan yang dirasakan, keseriusan yang dirasakan, manfaat dari rintangan yang dirasakan, dan isyarat atau tanda-tanda. Seseorang akan bertindak untuk mengobati penyakitnya, dia harus mengetahui dan merasakan bahwa dia rentan terhadap penyakitnya tersebut.

Teori self care terbukti juga memperkuat hasil penelitian ini. Empowerment education merupakan salah satu bentuk nursing agency yang dapat diberikan oleh perawat untuk meningkatkan pengetahuan klien kusta. (Nursalam, 2015). 
Peer group support adalah jenis dukungan sosial yang menggabungkan informasi (pengetahuan), penilaian (feedback) dan bantuan emosional (Solomon, 2004). Kegiatan support group merupakan salah satu bentuk individu mendapatkan pengetahuan (Notoatmodjo, 2010).

Penelitian Margaretha

menjelaskan dalam support group responden akan saling berdiskusi tentang pemahaman penyakit kusta dan keterampilan atau upaya menjaga dan merawat diri sendiri sehingga akan meningkatkan pengetahuan klien.

Sikap pencegahan cacat menunjukkan bahwa saat dilakukan pre-test pada kelompok intervensi berada pada tingkat sikap positif sedang. Setelah diberikan perlakuan, tingkat sikap kelompok intervensi mayoritas berubah ke tingkat sikap positif tinggi. Kelompok kontrol saat pre test mayoritas beradapada tingkat sikap positif sedang, sedangkan saat post test tingkat sikap responden kelompok kontrol mayoritas tetap berada tingkat kategori sikap positif sedang.

Sikap merupakan sebuah respons tertutup seseorang terhadap stimulus ataupun objek tertentu yang melibatkan faktor pendapat dan emosi yang bersangkutan. Sikap terdiri atas berbagai tingkatan yakni menerima (receiving), merespon (responding), menghargai (valuing), dan Bertanggung jawab (responsible) (Notoatmodjo, 2010) (Notoatmodjo, 2010).

Dalam teori health belief model juga menjelaskan bahwa sebuah sikap individu terhadap bagaimana melihat sebuah penyakit akan dipengaruhi oleh adanya faktor predisposisi seperti pendidikan dan pengetahuan. (Notoatmodjo, 2010). Teori model interaksi manusia Imogene $M$. King (1971) menjelaskan sikap diartikan sebagai gambaran seseorang tentang objek, orang, kejadian-kejadian yang akan berhubungan dengan latar belakang pendidikan, pengalaman masa lalu, konsep diri, sosial ekonomi, dan jenis kelamin (Nursalam, 2015).

Tujuan yang ingin dicapai dari empowerment education adalah terjadinya keberdayaan pada aspek afektif (sikap), kognitif (pengetahuan), dan psikomotorik (tindakan) yang akan terciptanya kemandirian (Onny, 1996).

Self-management education atau disebut juga empowerment education akan dapat merubah sebuah sikap dan keyakinan dari seseorang yang menderita penyakit kronis (Mufarokhah, 2016). Informasi yang diperoleh dari sesama responden dalam kegiatan support group dapat meningkatkan pengetahuan dan sikap terhadap penyakit kusta (Margaretha, 2014). Support group setiap anggota mendapat dukungan penuh dari sesama anggota, dapat mengekspresikan semua perasaan negatifnya, dan merupakan tempat bagi para anggota untuk mencari informasi (Underwood dan Gottlieb, 2000)

Hasil penelitian ini diperkuat teori self care bahwa adanya sebuah nursing agency melalui empowerment education, home based self care, dan peer support akan memberikan pengaruh terhadap conditioning factor dan self care agency. Salah satu conditioning factor adalah faktor predisposisi yang terdiri atas pengetahuan, dan sikap (Nursalam, 2015).

Teori Health Promotion Model menjelaskan bahwa terdapat beberapa variabel Health Promotion Model yatu (1) sikap yang berhubungan dengan aktifitas, (2) komitmen pada rencana tindakan, dan (3) adanya kebutuhan yang mendesak. Pengalaman sebelumnya dan faktor personal seperti empowerment education dan peer support akan merubah sikap individu dalam melihat sebuah perilaku promosi kesehatan (Nursalam, 2015).

Tindakan patuh minum obat kusta pada kelompok intervensi dan kelompok kontrol sama-sama berada pada tingkat kepatuhan tinggi dan sedang. Hasil post 
test responden pada kelompok intervensi mayoritas berada pada tingkat kepatuhan tinggi, sedangkan kelompok kontrol mayoritas berada pada tingkat kepatuhan sedang.

Analisis penelitian ini menunjukkan terdapat pengaruh intervensi terhadap tindakan kepatuhan minum obat.

Penelitian Mufarokhah (2016) menjelaskan bahwa self-management education atau disebut juga empowerment education dapat merubah kepatuhan berobat klien penyakit kronis. Penelitian Prastiwi (2010) menunjukkan kepatuhan berobat sangat berhubungan dengan tingkat kesembuhan dan mencegah kejadian kecacatan. Ketika individu diberikan pendidikan akan membuat pemahaman bahwa seberapa besar resiko kecacatan kusta tersebut.

Diperkuat oleh teori health belief model menjelasakan tingkat penerimaan yang benar tentang kerentanan, kegawatan, dan keuntungan tindakan, maka diperlukan isyarat-isyarat yang berupa faktor eksternal. Faktor-faktor tersebut, seperti sebuah edukasi, informasi dari peer (teman sebaya) atau anggota keluarga lain dari si sakit, dan sebagainya (Notoatmodjo, 2010).

Penelitian Yuswanto (2015) menjelaskan peran kelompok dukungan sebaya akan memberikan pengaruh yang signifikan terhadap kepatuhan dalam minum obat klien. Penelitian Diantiningsih (2012) menjelaskan peningkatan kepatuhan diet terjadi setelah diberikan intervensi peer support group sehingga kepatuhan cukup dan baik.

\section{SIMPULAN}

Empowerment education, dan peer support mempengaruhi pengetahuan, sikap, tindakan pencegahan cacat kusta pada klien kusta di Poli RS Kusta Sumberglagah.

\section{DAFTAR PUSTAKA}

Azwar, S 2007, Sikap Manusia Teori dan Pengukurannya, Pustaka Pelajar, Yogyakarta

Brakel, WH, Sihombing, S, Djarir, H, Beise, K, \& Laksmi, K 2012, 'Disability in people affected by leprosy: the role of impairment, activity, social participation, stigma and discrimination', Glob Health Action, diakses pada tanggal 6 november 2016, <http://www.globalhealthaction.n et/index.php/gha/view/18394>

Direktorat Jenderal Pengendalian Penyakit dan Penyehatan Lingkungan, 2012, Pedoman Nasional Program Pengendalian Penyakit Kusta, Jakarta, DJPP

Dinas Kesehatan Provinsi Jawa Timur, 2012, Profil Kesehatan Provinsi Jawa Timur Tahun 2012, diakses pada tanggal 30 Oktober 2016, <www.depkes.go.id/resources/do wnload/profil/PROFIL_KES_PR OVINSI_2012/15_Profil_Kes.Pro v.JawaTimur_2012.pdf>

Dinas Kesehatan Provinsi Jawa Timur, 2016, Laporan Kesehatan Provinsi Jawa Timur Tahun 2016, Dinkes Jatim, Surabaya

Kementerian Kesehatan RI, 2015, Menkes Canangkan Resolusi Jakarta Guna Hilangkan Stigma dan Diskriminasi Kusta, Diakses pada tanggal 30 Oktober 2016, < http://www.depkes.go.id/pdf.php? $\mathrm{id}=15012700001>$

Margareta, T, kusnanto \& Dewi, YS 2014, 'Pengetahuan, self efficacy dan stres pasien kusta melalui penerapan Support group dengan pendekatan teori adaptasi', Jurnal Ners, vol. 9, hal. 49-58

Masayoshi, I 2010, Manual Training leprosy rehabilitation Workers, 701 first Avenue, New York

Mufarokhah, H, Suhartono, T \& Dewi, YS 2016, 'Self Management Program Meningkatkan Koping, 
Niat Dan Kepatuhan Berobat Pasien PJK', Jurnal Ners, vol. 11, hal. 56-52

Notoatmodjo, S 2010, Ilmu Perilaku Kesehatan, Rineka Cipta, Jakarta

Notoatmodjo, S 2010, Promosi Kesehatan: Teori dan Aplikasi, Rineka Cipta, Jakarta

Nursalam, 2015, Metodologi Penelitian Ilmu Keperawatan Pendekatan Praktis edisi 4, Salemba Medika, Jakarta

Onny, S 1996, Pemberdayaan : Konsep, Kebijakan dan Implementasi, CSIS, Jakarta

Prastiwi, T 2010, 'Faktor-faktor yang Berhubungan dengan Cacat Tingkat II pada Penderita Kusta di RS Kusta Kediri Jawa Timur', Publish Undergraduated Theses, Universitas Airlangga, Surabaya

Putri, MA, Harmayetty \& Utomo, B 2016, 'Psycoeducative family therapy mempengaruhi pengetahuan, dukungan keluarga dan stigma kusta', Jurnal Ners, Vol. 11, hal 88-98

Rawleet, E 2011, Analytical Rvaluation of the Health Belief Model and Vulnerable Populations Conceptual Model applied to a Medically Underserved, Rural Population. Baltimore, University or Maryland, Uniter States of America

Sjamsoe, E, 2003, Kusta, FKUI, Jakarta

Susanto, N 2006, 'Faktor-faktor yang berhubungan dengan Tingkat kecacatan Penderita Kusta', Tesis, Universitas Gadjah Mada, Yogyakarta

Underwood, LG, Gotlieb, BH \& Cohen, S 2000, Social Support

Measurement and Intervention: A

Guide for Health and Social

Scientists, Oxford University

Press.

Wahyuni, S 2014, 'Aplikasi Leprosy Empowerment Education Terhadap Self Efiicacy,
Keteraturan Pengobatan, dan Kualitas Hidup Pada Pasien Kusta di Poli RS Kusta Kediri', Tesis, Universitas Airlangga, Surabaya

Wewengkang, K 2016, 'Pencegahan Kecacatan Akibat Kusta di Kota Manado', Jurnal Kedokteran Komunitas dan Tropik, vol. 4, no. 2

WHO, 2009, Enhanced Global Strategy for Further Reducing the Disese Burden Due to Leprosy, Mahatma Gandhi Marg, New Delhi

Yuswanto, TJA 2015, 'Peran Kelompok Dukungan Sebaya (KDS) dan Kepatuhan Minum Obat pada ODHA', Jurnal Pendidikan Kesehatan Vol. 4, no. 1, hal 6469 